\title{
A inserção do Nordeste na geoestratégia nacional de defesa e na economia global
}

\section{Beatriz Maria Soares Pontes}

\section{Introdução}

Antes de entrarmos na projeção do Nordeste brasileiro pela vasta área do Atlântico Sul, bem como citarmos os seus conteúdos estratégicos, devemos ressaltar que a plataforma mais avançada na direção leste daquele Oceano, representa, pela sua posição geográfica, a entrada efetiva do Atlântico Sul. Portanto, a nossa avaliação não poderá ater-se exclusivamente ao conteúdo interno e estratégico da Região Nordeste, mas avançarmos nos aspectos que envolvem o contexto total do Atlântico Sul. (PONTES, 2012).

Embora o diálogo, a cooperação, a ênfase no multilateralismo e o respeito ao direito internacional continuem a ser atributos importantes e desejáveis para o cenário internacional, a recomposição do sistema em base multipolar não é suficiente para garantir que, na atual transição, prevaleçam relações não conflituosas entre os Estados.

Nesse contexto, o Brasil assinala na sua política de defesa e na sua vocação para o diálogo, componentes essenciais para sua inserção afirmativa e cooperativa no plano internacional.

Assim, o custo do não engajamento do Brasil na construção da ordem internacional nascente pode ser muito maior do que o ônus, que é o investimento na capacitação, no preparo e no desenvolvimento de meios necessários ao exercício da soberania.

A consolidação de estruturas de governança multilateral é do interesse do Brasil, exigindo estreita coordenação entre as políticas externa e de defesa, na medida em que esta oferece àquela apoio e logística, imprescindíveis para a atuação do País, no cenário internacional.

A política de defesa determina a capacidade estatal de oferecer proteção ao povo brasileiro e de garantir a não ingerência externa em seu território e em suas águas jurisdicionais, inclusive, o espaço aéreo brasileiro, o leito marinho e o subsolo.

Isto significa que, a soberania da Nação, sua inserção econômica competitiva e seu desenvolvimento pleno, pressupõe capacidade de defesa condizente com as potencialidades e aspirações do País. Apesar das mudanças cada vez mais aceleradas das últimas décadas, a ordem internacional continua a ser determinada predominantemente pela relação entre Estados.

A defesa e proteção do Brasil diante de potenciais ameaças externas continuam a ser, assim, a missão essencial das Forças Armadas do País.

Outros desafios que se apresentam ao País dizem respeito à sua capacidade de fazer face aos

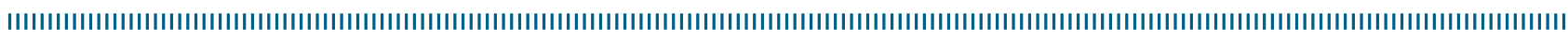
Como citar este artigo:

PONTES, Beatriz Maria Soares. "A inserção do Nordeste na geoestratégia nacional de defesa e na economia global”. In: RÜCKERT, A. A.; SILVA, A. C. P. da; SILVA, G. de V. (Orgs.). Geografia Política, Geopolítica e Gestão do Território: integração sul-americana e regiões periféricas. Porto Alegre: Editora Letra1, 2018, p. 343-356 DOI 10.21507/9788563800367-22 
chamados "conflitos do futuro", entre eles, as guerras de informação e os conflitos de pequena escala caracterizados por origem imprecisa e estruturas de comando e controle difusas, que operam com o uso de redes sociais.

Portanto, torna-se necessário fortalecer a capacidade de engajamento internacional do País. A participação efetiva de diversos setores sociais no debate nacional sobre defesa possibilita maior entendimento dessas questões.

O fenômeno da globalização trouxe consigo o agravamento de ameaças de naturezas distintas, como o narcotráfico, o tráfico de armas e a pirataria marítima. O agravamento da crise econômicofinanceira internacional indica também uma possível deterioração das condições sociais, energéticas e ambientais, com evidentes reflexos para a paz e a segurança no mundo.

O propósito brasileiro é trabalhar em prol da construção de uma comunidade global participativa e inclusiva, empenhando-se na promoção de uma "multipolaridade cooperativa". (BRASIL - LIVRO BRANCO DE DEFESA NACIONAL, 2012).

\section{As estratégias econômicas do Nordeste contemporâneo nas esferas agrícola e industrial}

\section{Áreas estratégicas agrícolas do Nordeste}

A reestruturação produtiva tornou-se um elemento importante no que concerne à agropecuária, uma vez que esta apresenta um aspecto fundamental para a formação da região, isto é, sua essência seletiva que manteve intocáveis algumas estruturas sociais, territoriais e políticas, enquanto outras se tornaram verdadeiros enclaves de modernização.

Como consequência da territorialização do capital no campo, houve o incremento da oligopolização do espaço agrícola brasileiro, seguido por um processo de fragmentação do referido, redundando numa nova divisão territorial do trabalho, afeta ao setor agrícola. Desta forma, as políticas públicas foram direcionadas a partir do modelo acima salientado para alguns espaços, dotando-os de um novo conjunto de objetos e de ações que os diferenciaram de outros espaços, promovendo a constituição de verdadeiras regiões produtivas. (SANTOS, 1985).

Entre o baixo curso do rio Açu, no Rio Grande do Norte e o baixo curso do rio Jaguaribe, no Ceará, existem regiões produtivas agrícolas. A formação destas regiões, além do critério das microrregiões do IBGE, das características naturais geográficas, da presença de ações efetuadas, tendo em vista o agronegócio e os respectivos agentes produtores do espaço, sugere o resgaste de outros aspectos, visando inserir em seu conjunto, cada município que iria consolidá-la:

- A influência da expansão agrícola sobre a região e, portanto, sobre cada município;

- A importância do agronegócio da fruticultura na consolidação da região como polo de destaque no conjunto regional nordestino e nacional;

- A existência de circuitos produtivos e círculos de cooperação, consolidando a região produtiva por meio do agronegócio da fruticultura, e

- A partir do desenvolvimento do agronegócio nessas regiões, a consideração em torno do significado de cada município na produção das principais culturas para exportação, assim como os municípios que se sobressaem no direcionamento de políticas públicas voltadas para o setor agrícola e aqueles em evidência na inserção de sistemas de objetos técnicos em seus espaços.

Sob a ótica espacial, um dos principais impactos da difusão de elementos do meio técnico-científicoinformacional (SANTOS, 1993) foi sua capacidade de articular espaços, promovendo as interações entre lugares, muitas vezes, distantes entre si.

Assim, selecionamos algumas variáveis para indicar tanto a expansão agrícola e a influência da modernização deste setor nas transformações mais recentes, que concorrem para reforçar o destaque e a existência das regiões produtivas agrícolas, quanto à presença de infraestruturas e o crescimento de outros equipamentos que concorrem para mudanças no processo produtivo e na organização dos espaços. Foram elas: 
- Área plantada e quantidades produzidas das culturas de exportação;

- Estabelecimentos do comércio que são ligados ao consumo produtivo, facilitando a compreensão da economia urbana associada à modernização agrícola;

- População Economicamente Ativa urbana e rural, revelando a concentração econômica, sobretudo, como o incremento da PEA urbana que reflete a dinâmica da economia urbana das cidades da região;

- Terminais telefônicos em serviço que revelam a circulação de informações, inclusive por redes de computadores;

- Emissoras de rádio e provedores da Internet, os quais refletem um incremento do consumo de energia (megawatts), além de serem responsáveis pela difusão da informação, mostrando como ocorre a integração com lugares cada vez mais distantes entre si;

- Terminais rodoviários em serviço que indicam a demanda por transporte de pessoas e mercadorias via sistema rodoviário;

- Análise da população residente que mostra o dinamismo da demografia nas regiões em estudo que, ao lado de uma revolução tecnológica da produção agropecuária e agroindustrial e as transformações nas relações de trabalho, desenvolve uma dinâmica demográfica e urbana, marcada por grande crescimento populacional, sobretudo, urbano;

- Número de empregos formais nos setores da economia, dado este que evidencia o dinamismo da economia, com a difusão de determinados segmentos econômicos;

- Existência de subcontratação nas relações de trabalho, mediante as quais percebemos a reestruturação nas relações de trabalho atuais; $\mathrm{e}$

- Evolução do emprego qualificado que sugere, por exemplo, a formação de mercados de trabalho com características dominantemente capitalistas, como é o caso da atividade agropecuária.

Quanto à articulação das regiões produtivas agrícolas em estudo, esta se dá em diversos níveis de organização espacial, a saber:
- Nível internacional, no caso do mercado mundial de frutas;

- Nível nacional, pela absorção de fluxos migratórios e aquisição de bens de consumo industrializados de outras regiões;

- Nível regional, mediando e enviando fluxos que atravessam a região para alguns portos (Suape, Natal, Pecém) e daí para outros lugares; e

- Nível sub-regional, nas interações espaciais entre as cidades da própria região.

A partir da análise das variáveis supracitadas, denominamos como uma região produtiva agrícola, o território formado por 25 municípios situados entre o nordeste cearense (região do baixo curso do rio Jaguaribe) e o noroeste potiguar (Mossoró e baixo curso do rio Açu). Esses municípios estão inseridos em três microrregiões geográficas do Instituto Brasileiro de Geografia e Estatística (IBGE), os quais são: Baixo Jaguaribe (CE), Mossoró (RN) e Vale do Açu (RN).

Sabemos que o território é formado por frações funcionais diversas. Assim, uma região produtiva pode ser considerada uma fração do território, desde que analisemos as suas relações internas e externas. Portanto, uma região moderna pode articular a escala local com a internacional, com base nas novas dinâmicas hegemônicas do agronegócio globalizado.

Desse modo, entendemos que a especialização flexível, em que os sistemas de produção verticalmente desintegrados e o rompimento das hierarquias rígidas têm sido acompanhados por uma mobilidade acelerada do capital, facilitou a busca de superlucros setoriais em qualquer parte do mundo.

As regiões produtivas abrangendo o baixo curso do rio Açu (RN) e o baixo curso do rio Jaguaribe (CE) ilustram esse tipo de especialização que foi absorvida pelo capital, pois, entre outros elementos, o "superlucro" de algumas multinacionais frutícolas foi obtido mediante barateamento substancial dos custos com mão de obra encontrada em abundância nessas regiões.

Observamos mais especificamente o caso da multinacional Del Monte Fresh Produce Ltda., 
uma das três principais empresas do setor de frutas do mundo que, em poucos anos, promoveu grandes transformações na produção, difundindo a agricultura científica e o agronegócio de frutas tropicais. Instalada no Vale do Açu, esta empresa produz, sobretudo, banana, especialmente no município de Ipanguaçu (RN). Já o Vale do Jaguaribe destaca-se com a produção de melão, no município de Quixeré e de abacaxi, no município de Limoeiro do Norte. Portanto, via terra e mão de obra, são estabelecidas as principais relações com o lugar, pois esta empresa traz de outros países todo o seu pacote tecnológico e serviços especializados, exportando quase toda a sua produção. (ELIAS, 2006).

O Baixo Açu, no Rio Grande do Norte, sempre se caracterizou por ser uma região cuja atividade principal foi, sobretudo, relacionada com o setor agrícola, predominando o complexo algodãopecuária-lavouras alimentares, associado à extração de cera de carnaúba. (VALVERDE, 1961). No Baixo Jaguaribe (CE), seu processo de territorialização destacou a agropecuária e o extrativismo vegetal como alicerces para seu processo de urbanização.

A junção desses aspectos materializa-se em condições naturais favoráveis à fruticultura que, aliadas aos aspectos infraestruturais e econômicos, como a construção dos reservatórios de recursos hídricos, o uso da irrigação, a melhoria nos sistemas viários, entre outros, tornam-se fatores de atração de empresas agrícolas modernas e mercado de insumos, favorecendo o estabelecimento das cadeias de produção de frutas.

Como decorrência do potencial da fruticultura, as regiões em estudo passaram a ser apontadas como essenciais e sustentáculos da economia regional nordestina proposta pelas novas estratégias do governo federal, isto é, um eixo privilegiado para que os grandes investimentos as tornem centros competitivos integrados aos mercados nacional e internacional. Assim, não só a produção agrícola da região é modificada, senão também, sua economia urbana, sua dinâmica populacional e o seu mercado de trabalho, que passam a responder de forma bastante diferenciada em relação aos períodos precedentes do processo histórico das regiões em tela. (GOMES, 2010).

\section{As estratégias industriais no Nordeste}

À medida que os avanços da indústria e a modernização do sistema e dos meios de transportes criaram condições para o rompimento das limitações regionais, observamos uma maior intensidade da concorrência inter-regional.

Nesse período teve início um novo processo de acumulação denominado integração produtiva. Este serviu de reforço ao anterior (articulação comercial), tendo como base a regionalização do grande capital produtivo através da presença de grupos oligopólicos, da grande empresa estatal e de grande parte do capital nacional, em todas as regiões brasileiras. (GUIMARÃES NETO, s.d.).

A presença induzida do grande capital, na região Nordeste, possibilitou um dinamismo e transformações de grande impacto que a partir das disponibilidades de recursos regionais, não teriam ocorrido com a mesma rapidez e intensidade verificadas nos anos 60 e 70. Porém, esse dinamismo não se deu de forma igualitária entre os estados da região, acarretando várias críticas à essa ação desenvolvimentista.

A SUDENE serviu como instrumento da expansão hegemônica do capitalismo monopolista. No que tange à transferência dos principais grupos econômicos do Centro-Sul, via implantação de fábricas e unidades produtivas, essas resultaram do programa de industrialização (integrado), assegurando a homogeneização monopolista do espaço econômico nacional. No tocante à formação e à expansão de conglomerados, destacamos que: vinte e quatro das cem maiores empresas do País possuíam projetos próprios ou implantados, em agosto de 1971, no Nordeste. Dessas, quatro eram estatais, seis de propriedade privada, predominantemente nacional e quatorze de propriedade estrangeira.

Para verificarmos a situação de homogeneização monopolística, sugerimos o exame da presença das empresas mais importantes em seus respectivos ramos industriais no processo de expansão no Nordeste. (OLIVEIRA, 1981). 
Assim, poderíamos constatar, não apenas uma homogeneização monopolística global, mas também, setorial. Neste caso, o sentido da expansão não teria sido outro senão a preservação de mercado para a consolidação de posições no ramo industrial.

Oliveira observou ainda que, dos 16 subsetores que assumiam a estrutura industrial do país, 11 estavam se reproduzindo na estrutura industrial do Nordeste. Esses representavam as empresas mais importantes dos subsetores e ramos. Destarte, questionou se isso representaria, de fato, uma concorrência com suas matrizes na região sudeste e nas demais regiões, pois, ao seu ver, esse comportamento representou uma estratégia que visou a consolidação de empresas cujas posições no ramo industrial já estavam definidas, porém levando-se em conta a possibilidade de se ganhar uma porção maior no mercado nacional.

O resultado desse processo foi uma estrutura industrial descomprometida com a formação e distribuição de renda. Ou seja, configurou-se uma estrutura industrial que não era função de um mercado regional, mas de um mercado nacional mais amplo. Assim, a política de fomento à industrialização do Nordeste não se traduziu numa melhoria real das condições de vida de sua população pela modificação de estruturas "arcaicas", mas converteu-se (pela elevação da taxa de lucro real) num excelente campo de aplicações, penetrando o espaço econômico da região pelas estruturas oligopolísticas que comandavam a indústria nacional. (OLIVEIRA, 1981). Isso foi equivalente a um controle de ramos industriais no Brasil e uma relação de divisão do trabalho entre setores industriais.

Para Oliveira, a expansão do capitalismo monopolista, via a "integração produtiva", contribuiu para a dissolução das "regiões", enquanto espaços diferenciados de apropriação de valor. Sobre os resultados desse programa, ainda que deixassem a desejar em termos de criação de empregos e não tivessem contribuído para modificar a estrutura fundiária da região, ele ponderou que foi "inegável que a economia do Nordeste integrou-se completamente à economia nacional". (OLIVEIRA, 1981, p. 126).
Observamos que a preocupação de Oliveira é pertinente e contributiva a uma avaliação mais crítica à nossa história, em relação ao processo de integração produtiva nacional. Particularmente, como uma experiência da integração, na qual a intervenção tecnicista do Estado resultou na recriação dos desequilíbrios (intrarregionais), no momento em que discutimos formas mais complexas e diversas, proporcionadas pela atual "integração competitiva".

Sabemos que o saldo em termos de dinamismo econômico regional deveu-se à disponibilidade de recursos naturais, associada à forte intervenção do Estado, sobretudo nas políticas setoriais, tornando possível uma integração via política de importação de produtos estratégicos da química e da petroquímica, inscrevendo a região como produtora de bens intermediários para a economia nacional. Entretanto, os fluxos financeiros dessas novas unidades, moldadas na ruptura com as economias tradicionais, não foram capazes de impulsionar os setores produtivos locais que deveriam impedir ou redimensionar a evasão de renda e sua canalização para o Centro-Sul, sob a forma de comércio ou intermediação financeira. Consequente à essa fragilidade, temos a revelação de que os efeitos de encadeamento desse modelo industrial foram negativos.

A discussão crítica do modelo impõe a reflexão de que, sob tais circunstâncias, a política governamental de incentivos fiscais e demais subsídios teria promovido a extensão das indústrias do Centro-Sul, integradas entre si e autônomas em relação ao restante da economia local. Disto resulta que, com a crise dos anos 80, o processo de desconcentração econômica das regiões mais industrializadas, em favor das menos industrializadas, viesse a se reverter, configurando uma nova reconcentração industrial.

Contudo, a partir da expansão das novas tecnologias, de base eletrônica e informática, bem como da alteração das regras de competitividade delineadas pelo novo padrão de acumulação flexível, também denominado de integração competitiva em mercados internacionais, é possível percebermos, na atualidade, um 
movimento de "forças" no sentido de uma nova concentração da atividade econômica na região sudeste, notadamente em São Paulo.

Conforme DINIZ (1996), tal concentração existe, primeiro, em função da preponderância de bens industrializados na estrutura de importações destinadas ao MERCOSUL. Em segundo, devido ao fator locacional (de maior proximidade geográfica). Assim, o resultado esperado foi que o comércio entre o Brasil e o MERCOSUL beneficiou as regiões sul e sudeste do País. Mas, em que medida isso se constituiria numa exclusão da região Nordeste?

As evidências desse impacto são mais visíveis, mediante a análise do desempenho das exportações nordestinas para o MERCOSUL. Segundo DINIZ (1996, p. 12):

De um ponto de vista absoluto, embora o volume das exportações da região Nordeste para o MERCOSUL apresentasse um crescimento de 96 para 421 milhões de dólares, esse acréscimo possui um ritmo inferior ao crescimento das exportações brasileiras, que saltaram de 1.320 para 6.154 milhões de dólares, no mesmo período.

A consequência disso foi percebida como uma queda de $7,3 \%$ para $6,8 \%$ da participação da região Nordeste no total exportado pelo Brasil, no período.

Vimos que a experiência da integração produtiva, apesar de todas as desigualdades que reproduziu, conseguiu estabelecer condições de "desconcentração" da economia, via uma articulação inter-regional, na qual as regiões se especializavam por complementaridade com as outras e seus mercados, "favorecendo" aquelas menos industrializadas, podendo-se afirmar que essa experiência se traduziu em um importante impulso à integração nacional e proporcionou um crescimento da economia nordestina, contudo, traduzindo-se em uma relativa redução das disparidades de níveis de desenvolvimento nos estados desta região.

No que diz respeito a fase de integração competitiva, via MERCOSUL, há uma tendência ao encaixe da economia nacional a uma estrutura que se articula com as áreas mais industrializadas do que com a base produtiva de cada uma das regiões periféricas, entre elas, a região Nordeste.
Tal comportamento suscita a possibilidade de exclusão dessas regiões, com indícios de ruptura da integração, formada no período anterior à atual fase de integração competitiva.

Para Albuquerque (1996), este novo modelo de desenvolvimento vem contribuindo para agravar e ampliar a vulnerabilidade socioeconômica do Nordeste, haja vista que o esforço de reestruturação produtiva brasileiro incide sobre os segmentos mais dinâmicos da economia à revelia das regiões periféricas, notadamente o Nordeste, em decorrência de seu aparelho produtivo ser de baixa competitividade, pouca integração interna, frágil articulação intersetorial e grave insuficiência de escala empresarial aliadas a outros fatores.

Entretanto, existe um consenso, que essa situação de vulnerabilidade não conduz o Nordeste, necessariamente, à uma exclusão. Admitimos a possibilidade de o Nordeste vir a se integrar, nacional e internacionalmente, desde que se adote uma estratégia de desenvolvimento regional que priorize os setores ou as atividades com relevante capacidade competitiva. Para tal, Albuquerque (1996) sugere a adoção de uma estratégia a ser desenvolvida baseada em uma dupla e diferenciada inserção (nacional e internacional), onde possamos buscar a dinamização da região através do comércio, de investimentos, do turismo, da modernização agrícola e agroindustrial (com ênfase no semiárido), entre outros. (MENEZES; MENEZES, 1998).

\section{A segurança e a defesa no Atlântico Sul}

Antes de entrarmos no mérito das questões referentes à segurança e à defesa no Atlântico Sul, faz-se mister efetuarmos um pequeno apanhado sobre as áreas geoestratégicas da infraestrutura socioeconômica, militar e cultural do Nordeste brasileiro.

Por Geoestratégia entendemos "a fundamentação geográfica das diretrizes estratégicas nacionais, abrangendo os aspectos Políticos, Psicossociais, Econômicos e de Segurança, tendo como horizonte não só a geração atual como as gerações futuras". (DALSASSO, 2008). É o que o Estado deve fazer com o patrimônio 
soberano para que a geração atual e as gerações futuras sintam-se consistentes, realizadas, felizes e, consequentemente, orgulhosas de sua nação.

A Geoestratégia trata do estudo das relações dos problemas estratégicos e os fatores geográficos. No que concerne à distinção entre Geoestratégia e Estratégia, os critérios mais utilizados são, por um lado, a escala geográfica, na qual os aludidos critérios norteiam estudos que considerem espaços maiores que aqueles visualizados pela Estratégia, que estuda o teatro de operações com um número maior de detalhes, logrando maior atenção nos espaços mais restritos do que aqueles que, em regra, interessam à Geoestratégia e, por outro, leva em conta a forma predominante de encarar os acidentes geográficos que a Estratégia tende a ver, sobretudo, como condicionantes, enquanto a Geoestratégia no centro das suas análises, os valoriza em função do seu eventual papel como objetivos ou fatores de poder.

As principais áreas geoestratégicas da infraestrutura socioeconômica, política, militar e cultural do nordeste brasileiro são: Aquífero Serra Grande (PI); Jazidas Minerais: Ferro (PI), Urânio (CE e BA) e Salgema (AL); Bases Aéreas: Alcântara (MA) e Barreira do Inferno (RN); Aeroportos: Recife (PE) e Salvador (BA); Portos: Itaqui e Ponta da Madeira (MA), Pecém (CE), Suape (PE) e Aratu (BA); Usinas Hidrelétricas: Paulo Afonso I, II, III e IV (PE), Xingó (AL) e Sobradinho (BA); Refinarias de Petróleo: LUBNOR (CE), Clara Camarão (RN), Suape (PE) e Landulpho Alves (BA); Distritos Industriais: Suape (PE) e Camaçari (BA); Entroncamento Comercial e Energético de Imperatriz (MA); Polo Farmacoquímico e Biotecnológico (PE) e Parques Nacionais: Sete Cidades e Capivara (PI).

Elas merecem ser lembradas porque representam o que de significativo tem essa região, internamente, sob a ótica geoestratégica, fato que não poderia ser ignorado quando analisamos a possibilidade da inserção do Nordeste, na Estratégia Nacional de Defesa.

Em primeiro lugar, é necessário salientar o estudo da segurança e da defesa no Atlântico Sul, uma vez que, como já foi dito antes, o Nordeste brasileiro é a entrada do Atlântico Sul, tratando-se de um território que contém áreas geoestratégicas de grande relevo, além de lograr, pela sua posição, uma localização que exige atenção no que concerne à segurança e à defesa nacional.

O Nordeste brasileiro, portanto, abre as portas para o Atlântico Sul, que é, sem dúvida, uma área estratégica tanto para os sul-americanos, quanto para os africanos.

País com maior costa atlântica do mundo, o Brasil tem, especial interesse na paz e na segurança do Atlântico Sul. Esse oceano possui áreas estratégicas relevantes como a "Garganta Atlântica", entre a costa do nordeste brasileiro e a África ocidental, espaço intercontinental de grande importância para o comércio mundial.

As passagens ao sul, que ligam o Atlântico ao Pacífico, constituem uma via alternativa ao canal do Panamá, principalmente para os navios de grande porte. A rota do cabo da Boa Esperança, conectando o Atlântico Sul ao oceano Índico é uma alternativa ao canal de Suez e, oferece também, o melhor acesso marítimo à Antártica. Para além do pré-sal, boa parte do petróleo que o Brasil importa vem de países na faixa equatorial do Atlântico.

As áreas marítimas estratégicas de maior prioridade e importância para o Brasil são representadas pelas águas jurisdicionais brasileiras (AJB), as quais incluem o mar territorial (mT), a zona contígua $(\mathrm{zC})$, a zona econômica exclusiva (zee) e a plataforma continental (PC), bem como a região compreendida entre o Paralelo 16 norte, a costa oeste da África, a Antártica, o leste da América do Sul e o leste das Antilhas menores.

O Brasil também dedica, junto a seus vizinhos da África Ocidental, especial atenção à construção de um ambiente cooperativo no Atlântico Sul, sob a égide da Zona de Paz e Cooperação do Atlântico Sul (ZOPACAS).

Criada em 1986 pelas Nações Unidas, a ZOPACAS conta, atualmente, com 24 membros: África do Sul, Angola, Argentina, Benin, Brasil, Cabo Verde, Camarões, Congo, Costa do Marfim, Gabão, Gâmbia, Gana, Guiné, Guiné-Bissau, Guiné Equatorial, Libéria, Namíbia, Nigéria, República Democrática do Congo, São Tomé e Príncipe, Senegal, Serra Leoa, Togo e Uruguai. 
Em termos diplomáticos, o reforço da ZOPACAS é importante para a defesa do País. O Atlântico Sul tem identidade histórica e características estratégicas próprias. A resolução n ${ }^{\circ} 41 / 11$, da Assembleia Geral das Nações Unidas, conclama os estados militarmente significativos de outras regiões a não introduzirem armamentos nucleares ou outros armamentos de destruição em massa no Atlântico Sul. Sua presença militar nesse oceano deve ser reduzida e, futuramente, eliminada. Conflitos e rivalidades estranhos ao Atlântico Sul não devem ser projetados sobre ele por estados situados em outras regiões. Ao renovar seu envolvimento com esses preceitos multilaterais, o Brasil deseja contribuir, de forma responsável e em colaboração com seus parceiros da ZOPACAS, para o aproveitamento do potencial de desenvolvimento socioeconômico da região do Atlântico Sul. (BRASIL, 2012, p. 35-36).

\section{As relações Brasil-África sob a ótica da segurança e da defesa}

Enquanto o Atlântico Sul condicionou o preparo e emprego das forças navais no quadro de defesa das Américas, no período da Guerra Fria, hoje essa área se apresenta para a política externa do País como prioridade estratégica e como eixo para a inserção internacional do Brasil.

Em consequência, dentro do quadro da chamada cooperação Sul-Sul, que se conformou na década de 1970 e, ganhou força no pós-Guerra Fria, o Brasil tem firmado uma série de acordos com países africanos, especialmente os localizados na costa ocidental do continente. Além das áreas econômica, política e tecnológica, a cooperação tem-se dado, também, no campo da segurança e da defesa.

Com o final da Guerra Fria, o papel do Atlântico Sul no contexto da segurança global, como parte da arquitetura de defesa do continente americano, perdeu o sentido que tinha no período anterior. Várias manobras conjuntas continuaram sendo realizadas, patrocinadas pelos EUA ou criadas de maneira bilateral ou multilateral entre Argentina, Brasil e Uruguai (AGUILAR, 2013).

No entanto, tiveram mais o caráter de fomento da confiança mútua, que de preparo para lutar contra um inimigo comum. Os exercícios entre Argentina, Brasil e Uruguai, voltados para o Atlântico Sul ganharam mais força a partir da década de 1990.

As marinhas da Argentina e do Brasil criaram a operação Araex que incluía o emprego de aviões e helicópteros navais na guerra no mar, com base em exercício semelhante realizado entre as armadas do Uruguai e do Brasil, denominado Uruex. A partir de 2002, os exercícios passaram a reunir as marinhas dos três países. Em 1997, Brasil e Argentina realizaram a Operação Temperex (ações anti-submarinos e de esclarecimentos aéreos), com o porta-aviões brasileiro São Paulo, conduzindo aeronaves S-2T argentinas. Naquele mesmo ano, os três países realizaram um exercício naval, tipo jogo de guerra, denominado Transamérica, versando sobre o controle de tráfego marítimo, a partir da simulação de uma crise regional em que seria necessária a adoção de medidas para a proteção do trânsito de navios mercantes. As três marinhas criaram, também, um jogo de guerra trilateral de manejo de crises em nível estratégico operacional. (AGUILAR, 2010, p. 303).

No continente africano, com o final da Guerra Fria, uma série de conflitos movidos pela luta ideológica entre as duas superpotências perdeu o sentido e as fontes de financiamento se encerraram, permitindo a resolução dos mesmos, como os casos de Angola e Moçambique. O fim do regime do apartheid, na África do Sul, abriu as portas daquele país para o relacionamento externo, ajudando no estreitamento dos laços com o Brasil.

Em 1993, a Argentina e a África do Sul criaram o exercício Atlasur, no bojo da ZOPACAS, com foco voltado para ações de superfície, antiaéreas, antisubmarinas e de guerra eletrônica, sendo testados, também, procedimentos de apoio logístico móvel e aperfeiçoada a interoperabilidade entre os meios navais e aeronavais dos participantes. A partir de 1995, a convite da Argentina, o Brasil e o Uruguai passaram a participar da manobra e oficiais paraguaios estiveram presentes como observadores. (AGUILAR, 2010, p. 299). 
No caso do Brasil, a Política de Defesa Nacional (PDN), aprovada em 2005, incorporou a concepção multidimensional da segurança, bastante discutida no âmbito da Organização dos Estados Americanos (OEA), durante a década de 1990, “abrangendo os campos político, militar, econômico, social, ambiental e outros", mantendo a defesa externa como função primordial das Forças Armadas. Dentre as diretrizes estratégicas, apresentou a intensificação do intercâmbio com as Forças Armadas das nações amigas, particularmente com as da América do Sul e as da África, lindeiras ao Atlântico Sul. (BRASIL. PR, 2005).

A PDN apresentou, ainda, que o Brasil participaria em missões de paz e ações humanitárias, de acordo com os interesses nacionais, confirmando as ações do governo nesse sentido, já a partir do final da década de 1980, onde se enquadra o envio de tropas armadas para as missões de paz da ONU, em Angola e Moçambique, em meados da década de 1990. No caso desses dois países, a língua portuguesa e o passado comum como colônias portuguesas, pesaram na decisão de uma maior participação do País, nos esforços de paz da ONU. Mas, indicou, também, uma maior importância dos assuntos africanos na agenda internacional brasileira. Além das citadas missões de paz, contemporaneamente, o Brasil tem estabelecida uma missão de paz no Haiti.

A Estratégia Nacional de Defesa (END), registrou que uma das preocupações mais agudas de defesa estava no Atlântico Sul. A identificação e a análise dos principais aspectos positivos e das vulnerabilidades levaram a END a determinar uma articulação das forças armadas "capaz de levar em consideração as exigências de cada ambiente operacional, em especial o amazônico e o do Atlântico Sul”. (MD; END, 2008, p. 45).

A END determinou que, na elaboração das hipóteses de emprego, a Estratégia Militar de Defesa deveria contemplar o emprego das Forças Armadas em decorrência da ameaça de conflito armado no Atlântico Sul. Em consequência, os planos de equipamento e articulação das Forças Armadas deveriam "contemplar uma proposta de distribuição espacial das instalações militares e de quantificação dos meios necessários ao atendimento eficaz das Hipóteses de Emprego", de maneira a possibilitar o aumento da presença militar nas áreas estratégicas do Atlântico Sul e da região amazônica. (MD, 2008, p. 49).

Na conferência de abertura do Seminário de Estratégias de Defesa Nacional, em novembro de 2012, o Ministro Celso Amorim levantou a preocupação com as tensões em países da África Ocidental, como o Mali e a Guiné Bissau, o narcotráfico associado ao terrorismo e à pirataria marítima, além do risco de se trazerem para o Atlântico Sul “organizações militares com outros propósitos ou visando a outros inimigos ou adversários”. Em seguida, afirmou que:

O entorno estratégico do Brasil, foco prioritário da lógica da cooperação é composto, de um lado, pela América do Sul, tocando a Antártica e, de outro lado, pelo Atlântico Sul, estendendo-se até a orla ocidental da África. (AMORIM, 2012, p. 10).

No mesmo sentido do discurso oficial e dos documentos de defesa, várias ações do governo brasileiro contemplaram os países africanos. Foram assinados acordos de cooperação no domínio da defesa com Cabo Verde (MRE 1994b), em 1994, África do Sul (MRE 2003), em 2003, Guiné Bissau (MRE 2006), em 2006, com Moçambique (MRE 2009b) e Namíbia (MRE 2009a), em 2009, Nigéria (MRE 2010c), Senegal (MRE 2010d), Angola (MRE 2010a) e Guiné Equatorial (MRE 2010b), em 2010.

Em linhas gerais, se destinavam a: promover a cooperação nas áreas de pesquisa edesenvolvimento, apoio logístico e aquisição de produtos e serviços de defesa; partilhar conhecimentos e experiências adquiridas no campo de operações, na utilização de equipamentos militares de origem nacional e estrangeira, bem como no cumprimento de operações internacionais de manutenção da paz; partilhar conhecimentos nas áreas da ciência e tecnologia, promovendo ações conjuntas de treinamento e instrução militar, exercícios militares combinados, bem como a correspondente troca de informações e colaborar em assuntos relacionados a equipamentos e sistemas militares. A cooperação se realizaria por meio de visitas 
de delegações de alto nível; reuniões entre as instituições de defesa; intercâmbio de instrutores e estudantes de instituições militares; participação em cursos teóricos e práticos, estágios, seminários, conferências, debates e simpósios realizados em entidades militares, bem como em entidades civis de interesse para a defesa; visitas de navios de guerra e aeronaves militares; eventos culturais e desportivos; facilitação das iniciativas comerciais relacionadas a materiais e serviços vinculados à área de defesa e implementação e desenvolvimento de programas e projetos de aplicação de tecnologia de defesa, com a possibilidade de participação de entidades militares e civis de interesse estratégico para as partes.

Em 2004, sob a égide do Acordo Geral de Cooperação que havia sido assinado em 1981, Brasil e Moçambique realizaram um ajuste complementar relacionado com segurança pública. A cooperação nesse campo implicou na coordenação de estratégias e troca de informações sobre programas nacionais referentes à prevenção e combate ao crime; cooperação técnica orientada pela experiência brasileira da implantação do Sistema Único de Segurança Pública; ações de formação de pessoal, em especial, ações de capacitação de docentes e formação de formadores, de cooperação no domínio de implantação dos sistemas de gestão do conhecimento e informações, de estatísticas, de pesquisas aplicadas e de elaboração de diagnósticos de segurança pública e justiça criminal, além da realização de estudos visando à modernização da área de gestão das instituições de segurança pública. A Secretaria Nacional de Segurança Pública do Ministério da Justiça do Brasil ficou responsável pela execução das ações e a ABC como responsável pela coordenação, acompanhamento e avaliação das ações. (MRE, 2004a).

Em 2009, um Ajuste Complementar ao Acordo Básico de Cooperação Técnica e Científica que existia entre o Brasil e a Guiné-Bissau, de 1978, previu a implementação de um Centro de Formação das Forças de Segurança naquele país, com o objetivo de contribuir para a reestruturação e modernização do setor de segurança e defesa, ficando a Polícia Federal brasileira responsável pelas ações decorrentes do ajuste. (MRE, 2009c).

Em 2010, uma das áreas da parceria estratégica firmada com Angola foi a de segurança pública e defesa. As diretrizes, nesse domínio, apresentaram o estímulo à cooperação entre os ministérios da defesa e os órgãos de segurança pública e a manutenção de "consultas regulares sobre temas bilaterais, regionais e multilaterais", incluindo as iniciativas no âmbito da Zona de Paz e Cooperação no Atlântico Sul e a "cooperação para a solução de conflitos na África e em outras regiões, inclusive construção da paz em situações pós-conflito". No campo da cooperação técnica, científica e tecnológica, a parceria contemplou ações para o desenvolvimento de recursos humanos e pesquisas conjuntas nas áreas da indústria naval, segurança pública e defesa. Foi, ainda, estabelecida uma Comissão Bilateral de Alto Nível para "coordenar, acompanhar, avaliar, orientar e assegurar a implementação da parceria”. (MRE, 2010e).

Dos países da costa atlântica africana, a Namíbia se firmou como a maior receptora da cooperação brasileira no campo da segurança e defesa. Em 1994, o Acordo Naval assinado entre os dois países deu início ao relacionamento entre as marinhas dos dois países com o objetivo de "criar e fortificar a Ala Naval do Ministério da Defesa da Namíbia”. Todas as despesas de traslado e estadia no Brasil, bem como dos militares brasileiros que ficariam naquele país como oficiais de ligação, ficaram a cargo do então Ministério da Marinha brasileiro. (MRE, 1994a).

$\mathrm{Na}$ época, foram disponibilizadas vagas para formação de oficiais e praças daquele país nas escolas navais brasileiras e realizado um estágio inicial para 145 marinheiros namibianos no Grupamento de Patrulha Naval do Sudeste, no Rio de Janeiro. (MD; MB, 2011).

Em 2001, o governo de Fernando Henrique Cardoso assinou um novo Acordo de Cooperação Naval com o mesmo objetivo do anterior. Por ele, a Marinha Brasileira deveria assistir na organização do Serviço de Patrulha Marítima daquele país capaz de proteger seus interesses em suas águas internas, mar territorial e zona econômica exclusiva, fornecer embarcações e 
“assistir no planejamento e desenvolvimento de uma infraestrutura apropriada à atracação e suporte logístico para tais embarcações”. Os custos do treinamento e avaliação realizados no Brasil passaram a ser do governo da Namíbia e foi estabelecida a Missão Naval Brasileira na Namíbia. (MRE, 2001).

O acordo gerou uma série de ações decorrentes. Em 2004, a Corveta Purus, que havia sido “aposentada", foi transferida para a Namíbia, sendo batizada naquele país de "NS Lt-Gen Dimo Hamaambo". No mesmo ano, foi acertado o fornecimento de embarcações construídas no Brasil e, em 2006, a marinha brasileira criou Grupos de Apoio Técnico e enviou militares para a base de Walvis Bay.

Em 2009, foi entregue o primeiro naviopatrulha construído no Brasil, batizado de "Brendan Sinbwaye". (BASTOS, 2011). Foram disponibilizadas vagas para os namibianos na Escola Naval, nos cursos de Aperfeiçoamento para Oficiais em Hidrografia e de Formação de Oficiais do Centro de Instrução Almirante Wandenkolk (CIAW), em cursos de especialização e de formação de marinheiros e soldados. (MD; MB, 2011). As ações incluíram, ainda, a cooperação para a criação do Batalhão de Infantaria de Fuzileiros Navais namibiano e a realização de curso de formação de soldados; o desenvolvimento do Cerimonial da Marinha; a promoção de ações conjuntas de instrução e treinamento militar; exercícios militares conjuntos; troca de informações e a colaboração em assuntos relacionados com sistemas, softwares e equipamentos, dentre outros. (MD; MB, 2011).

Em abril de 2010, a Missão Naval na Namíbia contava com cinco oficiais e onze praças. (MD; MB, 2011; PRADO, 2009). No início daquele ano, ocorreu a formatura da primeira turma de Soldados Fuzileiros Navais da Namíbia formados pela Marinha do Brasil. Os soldados assumiram funções no "Marine Corps Battalion", futuro Batalhão de Infantaria de Fuzileiros Navais da Namíbia. (Revista Forças Armadas, 2011).

No âmbito do IBAS, em 2005, iniciou-se a realização das operações conjuntas denominadas
"IBSAMAR", reunindo as marinhas do Brasil, Índia e África do Sul, no litoral sul africano, entre as cidades do Cabo e Simon's Town. (MD; MB, 2011).

Em 2006, fruto do acordo de cooperação de 2003, as forças aéreas do Brasil e da África do Sul iniciaram o desenvolvimento de um projeto de míssil de curto alcance, capaz de realizar manobras para atingir alvos durante o voo e com sistema de detecção infravermelho, denominado A-Darter. (RANGEL, 2010, p. 48).

As escolas militares de formação e de altos estudos do Exército passaram a receber alunos dos países africanos, especialmente dos de língua portuguesa. Na Academia Militar das Agulhas Negras, em 2011, dos 42 cadetes estrangeiros que se encontravam matriculados, 27 eram de países da CPLP (dez de Angola, dez de Moçambique, dois de Cabo Verde, um da Guiné Bissau e quatro de São Tomé e Príncipe).

A Escola de Comando e Estado-Maior do Exército (ECEME) tem um curso voltado para oficiais de nações amigas (ONA), que recebe em média 11 alunos por ano, dentre eles, africanos. Em 1999, recebeu um angolano e, em 2007 e 2011, oficiais da Nigéria.

Com o Gabão, a cooperação na área do ensino superior, abrangeu a formação de militares daquele país nas escolas de ensino superior da Marinha do Brasil e os dois governos demonstraram interesse em desenvolver a cooperação nos setores de formação de militares, treinamento para as operações de combate em ambientes tropicais e na luta contra a biopirataria. (MRE, 2004b).

Em 2012, o ministro da Defesa da Mauritânia, visitou o Brasil e, na reunião com o Ministro Celso Amorim, tratou da possibilidade de realização de exercício conjunto entre as duas marinhas. (MURMEL, 2013). Há contatos estreitos com Cabo Verde para capacitação na área naval, de patrulha aérea e com o Exército na área de manutenção da ordem. (AMORIM, 2012, p. 12).

Em 2013, o navio-patrulha Apa, construído pela empresa inglesa BAE Systems, em sua viajem do porto de Portsmouth, no Reino Unido, com destino ao Brasil, participou de missões na Mauritânia, Senegal, Angola e Namíbia. (MURMEL, 2013). O 
mesmo havia acontecido anteriormente na viagem inaugural do navio patrulha oceânico Amazonas, que realizou exercícios conjuntos e estreitou laços com as marinhas de Cabo Verde, Benin, Nigéria e São Tomé e Príncipe. (AMORIM, 2012, p. 12).

No âmbito da Força Aérea, a Academia da Força Aérea (AFA) formou pilotos de Angola, Moçambique e Guiné Bissau e o governo brasileiro acertou a venda de aviões de ataque leve Super Tucano para a Mauritânia e Burkina Faso. (AMORIM, 2012). A Comunidade dos Países de Língua Portuguesa (CPLP) se tornou um fórum internacional bastante atuante nas discussões no campo da segurança e defesa. Com base no documento jurídico denominado Protocolo de Cooperação da CPLP no Domínio da Defesa, foram criadas a Reunião de Ministros da Defesa Nacional, a Reunião dos Chefes de Estado-Maior de Defesa e o Centro de Análise Estratégica (CAE), com a finalidade de discutir a profissionalização das Forças Armadas, a ética e a profissão militar.

No âmbito da CPLP, foi criada a Operação Felino, em outubro de 2000, realizada anualmente em sistema de rodízio, com a participação de elementos dos exércitos de cada um dos países da Comunidade e com um Estado-Maior Multinacional. A operação foi concebida no tema das missões de manutenção da paz e de ajuda humanitária. (BRASIL; EB, s/d).

O Brasil estabeleceu aditâncias militares junto às embaixadas brasileiras na África do Sul, Nigéria, Angola e em São Tomé e Príncipe e, a Agência Brasileira de Cooperação, apoiou com bolsas de estudos a formação de quadros na área de segurança e defesa por meio da chamada “cooperação em conhecimento". (FKA, 2009).

A ABC operacionalizou o memorando de entendimento assinado pelo Ministério da Defesa do Brasil e pelos países da África para a realização de cursos e treinamentos nas três forças armadas. Houve, ainda, a previsão do estabelecimento de uma academia de polícia na Guiné-Bissau e de treinamento contínuo de policiais, a fim de auxiliar o país na reestruturação das forças de segurança pública. (FKA, 2009; AGUILAR, 2013).

\section{Considerações finais}

Após essa trajetória em torno da temática sobre a Inserção do Nordeste na Economia Global e na Geoestratégia Nacional de Defesa pensamos que é perfeitamente justa a inserção do Nordeste na Estratégia Nacional de Defesa, tendo em vista o que foi analisado precedentemente, bem como entendemos que, através de atividades agrícolas e industriais baseadas em tecnologias de ponta, o Nordeste teve condições de ingressar no processo global, ainda que a região tivesse sido prejudicada pela mão de obra barata e pela inadequada distribuição da renda resultantes das aludidas atividades.

Finalmente, constatamos que a segurança e a defesa do Atlântico Sul são metas estratégicas prioritárias que devem nortear as relações Sul-Sul. Entendemos que o Brasil, assim como as demais nações integrantes do hemisfério sul, não podem ignorar as relações Sul-Norte, sobretudo, em um mundo muito interdependente.

Entretanto, para nós torna-se uma missão imprescindível, a agilização do intercâmbio em todas as esferas, entre as nações do Hemisfério Sul, onde nos encontramos, o qual constitui uma extensa área que apresenta recursos naturais e humanos que não podem ser ignorados, os quais sugerem esforços acentuados para a sua dinamização administrativa, comercial, industrial e financeira, além de substanciais impulsos relativos à educação, saúde, saneamento, habitação, transportes e segurança, com a finalidade de tornar vastas porções do Hemisfério Sul menos desiguais, se comparadas às várias áreas desenvolvidas do Hemisfério Norte.

\section{Referências}

AGUILAR, S. L. C. Segurança e Defesa no Cone Sul: da rivalidade da Guerra Fria à Cooperação Atual. São Paulo: Porto de Ideias, 2010.

AGUILAR, S. L. C. Atlântico Sul: As Relações do Brasil com os Países Africanos no Campo da Segurança e Defesa. Austral: Revista Brasileira de Estratégia e Relações Internacionais. v.2, n.4, p. 49-71. Jul-Dez, 2013.

ALBUQUERQUE, R. C. de. O Nordeste, o Brasil e o Novo Ciclo de Crescimento. In: Simpósio Internacional a Reforma 
do Estado e o Desenvolvimento do Nordeste na Economia Globalizada. Salvador, 1996. (mimeo).

AMORIM, C. "Defesa Nacional e Pensamento Estratégico Brasileiro". In: Conferência do Ministro da Defesa na abertura do Seminário Estratégias de Defesa Nacional. Brasília, 27 de novembro, 2012.

BASTOS, E. C. S. A Marinha do Brasil e sua Projeção no Continente Africano. Juiz de Fora: UFJF, 2011. Disponível em: <http://www.ecsbdefesa com.br/defesa/fts/MBCA. pdf $>$. Acesso em: 16/08/2012.

BRASIL. PR. Decreto $n^{\circ} 5.484$, de 30 de junho de 2005. Aprova a Política de Defesa Nacional e dá Outras Providências. Brasília, 30 jun. 2005.

BRASIL. EB. s.d. Militares das Forças Armadas participaram, no mês de março, do Exercício Felino, que ocorreu em Angola, na regiẫo de Cabo Ledo, na África. Disponível em: <https://www.exercito.gov.br/c/journal/view_article_ content?groupld=13903\&articlel=499772ion=1.0. $>$ Acesso em: 20/03/2013.

BRASIL. Livro Branco de Defesa Nacional. 2012. Disponível em: <http://www.defesa.gov.br/arquivos/2012/mes07/ ibdn.pdf $>$. Acesso em: 08/04/2016.

DINIZ, C. C. O Nordeste e o Mercosul. In: Simpósio internacional A reforma do estado e o desenvolvimento do Nordeste na economia globalizada. Salvador, 1996. (mimeo).

ELIAS, D. Agronegócio e Desigualdades Socioespaciais. In: ELIAS, D.; PEQUENO, R. (orgs.). Difusão do Agronegócio e Novas Dinâmicas Socioespaciais. Fortaleza: BNB, 2006.

FKA. Relatório sobre a VI Conferência do Forte de Copacabana. Rio de Janeiro, 12/13 de novembro, 2009. Disponível em: <https://www.kas.de/wf/doc/kas_18106-15225-30.pdf?091202194047>. Acesso em: 21/03/2013.

GEOPOLÍTICA E GEOESTRATÉGIA. Disponível em: <https:// www.cofecon.org.br/noticias/colunistas/ Humbertodalsasso/1526-geopolitica-e-geostrategia. htm. Acesso em:03/05/2016>.

GOMES, I. R. Globalização e Novas Regiões Produtivas no Nordeste Brasileiro. Mercator - Revista de Geografia da UFC. Vol. 9, No 20, p. 57-74. Set./Dez., 2010.

GUIMARÃES NETO, L. Questão Regional no Brasil: Reflexões sobre Processos Recentes. (mimeo).

MD. END - Estratégia Nacional de Defesa. 2008.

MD. MB. "Centro de Comunicação Social da Marinha". Brasília. 2011. Disponível em: <http://www.mar.mil. br/menu_h/noticias/ccsm/cooperacao_BrasilNamibia. htm >. Acesso em: 16/08/2012.

MENEZES, A. M. F.; MENEZES, E. V. O Nordeste Brasileiro no Processo de Reestruturação Econômica: Inclusão ou Exclusão. Sitientibus, $n$. 18. p. 75-98, Jan./Jun., 1998.

MRE. 1994a. Acordo de Cooperação entre o Governo da República da Namíbia e o Governo da República Federativa do Brasil. Windhoek, 04 de março.

MRE. 1994b. Acordo sobre Cooperação Técnica no Domínio Militar entre o Governo da República Federativa do Brasil e o Governo da República de Cabo Verde. Praia, 21 de dezembro.

MRE. 2001. Acordo entre o Governo da República Federativa do Brasil e o Governo da República da Namíbia sobre Cooperação Naval. Windhoek, 03 de dezembro.

MRE. 2003. Acordo entre o Governo da República Federativa do Brasil e o Governo da República da África do Sul sobre Cooperação em Assuntos Relativos à Defesa. Cidade do Cabo, 04 de junho.

MRE. 2004a. Ajuste Complementar ao Acordo Geral de Cooperação entre o Governo da República Federativa do Brasil e o Governo da República de Moçambique no Âmbito da Segurança Pública. 31 de agosto.

MRE. 2004b. Comunicado Conjunto da Visita de Estado de sua Excelência o Presidente Luiz Inácio Lula da Silva à República Gabonesa. Libreville, 28 de julho.

MRE. 2006. Acordo sobre Cooperação no Domínio da Defesa entre o Governo da República Federativa do Brasil e o Governo da República da Guiné-Bissau. Brasília. 06 de junho.

MRE. 2009a. Acordo entre o Governo da República Federativa do Brasil e o Governo da República da Namíbia sobre Cooperação no Domínio de Defesa. Windhoek, $1^{\circ}$ de junho.

MRE. 2009b. Acordo sobre Cooperação entre o Governo da República Federativa do Brasil e o Governo da República de Moçambique no Domínio da Defesa. Maputo, 26 de março.

MRE. 2009c. Ajuste Complementar ao Acordo Básico de Cooperação Técnica e Científica entre o Governo da República Federativa do Brasil e o Governo da República da GuinéBissau para Implementação do Projeto Centro de Formação das Forças de Segurança da Guiné Bissau. Brasília, 07 de dezembro.

MRE. 2010a. Acordo de Cooperação entre a República Federativa do Brasil e a República de Angola no Domínio da Defesa. Brasília, 23 de junho.

MRE. 2010b. Acordo entre o Governo da República Federativa do Brasil e o Governo da República da Guiné Equatorial sobre Cooperação em Matéria de Defesa. Malabo, 05 de junho.

MRE. 2010c. Acordo sobre Cooperação entre o Governo da República Federativa do Brasil e o Governo da República Federal da Nigéria no Domínio da Defesa. Brasília, 22 de julho.

MRE. 2010d. Acordo sobre Cooperação entre o Governo da República Federativa do Brasil e o Governo da República do Senegal no Domínio da Defesa. Brasília, 03 de agosto. MRE. 2010e. Declaração Conjunta sobre o Estabelecimento de Parceria Estratégica entre a República Federativa do Brasil e o Governo da República de Angola. Brasília, 23 de junho. MURMEL, N. NPaOc Apa Inicia Viagem ao Brasil com Foco na Cooperação com a África. Poder Naval. 2013. Disponível em: <https://www.naval.com.br/blog/tag/ marinha-dobrasil/\#ixzz2NjatQmUW >. Acesso em: 06/09/2016.

OLIVEIRA, F. de. Elegia para uma (Re)ligião. 4.ed. Rio de Janeiro: Paz e Terra, 1981. 
PONTES, B. M. S. O Valor Estratégico do Promontório Nordestino. Revista de Geopolítica, v. 3, n. 2, p. 4-36. Jul./Dez., 2012.

PRADO, A. Namíbia e Brasil Apostam na Cooperação Militar e Comercial. Revista África 21. 2009. Disponível em: <https://www.africa21digital.com/noticia. $\mathrm{kmf}$ ?cod=8311085\&canal=40 >. Acesso em: 16/08/2016.

RANGEL, R. Brasil e África do Sul: Desenvolvimento de Novo Míssil. Inovação em Pauta, n. 9, p. 48-49, Mai./ Jun., Brasília: Finep, 2010.
Revista Forças Armadas. 2011. Disponível em: <https:// www.revistaforcasarmadas.com.br/revista/estrutura/ marinhado-brasil-forma-primeira-turma-de-soldadosfuzileiros-navais-da-namibia>. Acesso em: 16/08/2016. SANTOS, M. Espaço e Método. São Paulo: Nobel, 1985.

SANTOS, M. Urbanização Brasileira. São Paulo: Hucitec, 1993.

VALVERDE, O.; MESQUITA, M. G. C. Geografia Agrária do Baixo Açu. Revista Brasileira de Geografia. Ano XXIII. n. 3, p. 455-492, Jul./Set., 1961.

\section{Beatriz Maria Soares Pontes}

Possui Graduação em Geografia pela Universidade de São Paulo (1960), Mestrado em Geografia pela Universidade de Paris I (Sorbonne) (1971), Doutorado em Ciências Humanas pela Universidade de São Paulo (1983), Professora Titular do Departamento de Geografia da UFRN (2006) e Livre-Docência em Geografia pela UNESP (2008). Atualmente é professora titular aposentada da Universidade Federal do Rio Grande do Norte e docente integrada à equipe que trabalha em pesquisas sobre Movimentos Socioterritoriais e Dinâmicas Espaciais do Departamento de Geografia da UFPE e membro do Centro de Estudos Geopolíticos e Relações Internacionais (CENEGRI-RJ).

E-mail: beatrizmariasoares@ig.com.br 